\title{
Self-Incompatibility in S-RNase-Based Systems: Are there Differences in the Pollen Rejection Mechanisms Among Species?
}

ISSN: 2637-7659

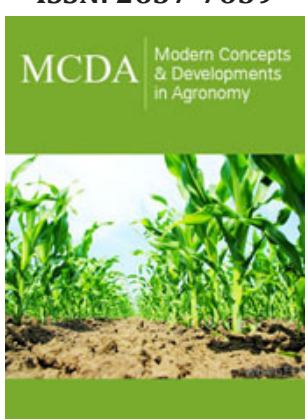

*Corresponding author: Felipe Cruz García, Departamento de Bioquímica, Facultad de Química, Universidad Nacional Autónoma de México, Cd. Mx., 04510, México

\section{Submission: 眥 March 12, 2021}

Published: 㘹 March 19, 2021

Volume 8 - Issue 2

How to cite this article: Javier Andrés Juárez Díaz, Yuridia Cruz Zamora, Felipe Cruz García. Self-Incompatibility in S-RNase-Based Systems: Are there Differences in the Pollen Rejection Mechanisms Among Species?. Mod Concep Dev Agrono. 8(2). MCDA. 000684. 2021. DOI: 10.31031/MCDA.2021.08.000684

Copyright@ Felipe Cruz García. This article is distributed under the terms of the Creative Commons Attribution 4.0 International License, which permits unrestricted use and redistribution provided that the original author and source are credited.
Javier Andrés Juárez Díaz ${ }^{1}$ Yuridia Cruz Zamora² and Felipe Cruz García ${ }^{2 *}$

${ }^{1}$ Departamento de Biología Comparada, Facultad de Ciencias, Universidad Nacional Autónoma de México

${ }^{2}$ Departamento de Bioquímica, Facultad de Química, Universidad Nacional Autónoma de México

\begin{abstract}
Several barriers occur among flowering plants to prevent self-fertilization by increasing and maintaining the species genetic variability. From all these barriers, self-incompatibility (SI) is one of the most effective avoiding endogamy. Genetic control in SI relies on the polymorphic $S$ locus, where both pollen and pistil $S$ determinants are encoded. Based on the pollen $S$ phenotype, diploid or haploid, there are two kinds of genetic control in the SI systems: the sporophytic and the gametophytic. In the gametophytic SI systems, two mechanisms are currently unraveled. One exclusive to Papaveraceae and the other one, known as the S-RNase-based SI, which is present in more divergent taxa: Plantaginaceae, Rosaceae, Rubiaceae, Rutaceae, and Solanaceae. The more in-depth studies on the molecular mechanism have been mainly done in Solanaceae, particularly in Petunia and Nicotiana, achieving significant advances by different genetic, molecular, biochemical, and cellular approaches, resulting in two models to encompass further evidence to explain it: the collaborative and the compartmentalization model. Both models, however, seem to be excluding each other. Here we will discuss the evidence and the information around these explanations and will discuss the possibility of why it has been so challenging to find an integrative hypothesis to understand this critical evolutionary process within angiosperms.
\end{abstract}

Keywords: Self-incompatibility; Solanaceae; Pollination; S-RNase, SLF, Nicotiana, Petunia, Collaborative; Compartmentalization

Abbreviations: SI: Self-Incompatibility/Self-Incompatible; SSI: Sporophytic SI; GSI: Gametophytic SI; PCD: Programmed Cell Death; PT: Pollen Tube; EM: Extracellular Matrix; STT: Stylar Transmitting Tissue; MG: Modifier Gene; Trx: Thioredoxin

\section{Introduction}

Self-incompatibility (SI), defined as the inability to produce zygote after self-pollination in fertile plants [1,2], is one of the main barriers in plants preventing inbreeding while promoting genetic variability in future generations.

Among angiosperms, SI is broadly classified as heteromorphic and homomorphic systems [1]. Heteromorphic SI is exhibited in species with two (distily) or three (tristily) floral morphs, while homomorphic one is in species with only one floral morph $[3,4]$.

The homomorphic SI systems have been extensively studied and analyzed under genetic, biochemical, and molecular approaches, exhibiting significant advances in understanding the pollen rejection molecular basis.

SI is a selective mechanism that discriminates between self- and non-self-pollen, preventing self-fertilization by rejecting self-pollen (incompatible cross). Pollen rejection occurs as the result of a complex pollen-pistil interaction network, that is, as the starting point, genetically regulated by the single multiallelic $S$ locus [5,6], except for some grasses (Poaceae), in which two loci $(S$ and $Z$ ) control self-pollen rejection $[7,8]$.

Both male (pollen expressed) and female (pistil expressed) specificity determinantencoding genes are tightly linked within the $S$ locus. In the pistil -formed by diploid cells-, both $S$ alleles are codominant, and therefore, it can recognize and reject any pollen portraying any of the same $S$ alleles. Recognition and rejection of self-pollen occur when the pollen $S$-allele matches one of the pistil $S$-alleles in a heterozygous plant [9]. 
On the pollen side, the $S$ product may have a sporophytic origin or a gametophytic one. In the sporophytic SI (SSI), the pollen exhibits a diploid $S$ recognition phenotype determined by the mother plant. In the gametophytic SI (GSI), the pollen $S$ phenotype depends on its haploid genotype after meiosis giving origin to the $S$ haplotype. In SSI, the pollen compatibility phenotype is granted by the anther (a diploid tissue), while in the GSI, the compatibility phenotype derives from the pollen haploid genotype $[10,11]$.

The SSI is a more restrictive pollen rejection mechanism because pollen will carry on its surface two $S$-proteins synthesized by the anther tapetum. For example, an $S_{1} S_{2}$ plant will deposit the
$S_{1}$ and $S_{2}$-proteins on the pollen grain exine. If this pollen lands on an $S_{1} S_{2}$ stigma, it will be rejected. Even more, if pollen lands on $S_{1} S_{3}$ or $S_{2} S_{4}$ stigmas, it will also be rejected, but no for $S_{3} S_{4}$ stigmas. By contrast, GSI is slightly more flexible. For instance, in a plant $S_{1} S_{2}$, $50 \%$ of the pollen grains will display $S_{1}$ haplotype and $50 \% S_{2}$. The pistil will reject either pollen grains (Figure 1). However, pollen may come from a close-related individual. For example, in an $S_{1} S_{2}$ $\mathrm{X} S_{1} S_{3}$ cross, only $S_{1}$ pollen will be rejected but not $S_{3}$ (Figure 1), which does not occur in SSI (where pollen would display an $S_{1} S_{3}$ phenotype). Therefore, while in SSI, there are only compatible and incompatible crosses, semi-compatible crosses may occur in GSI.

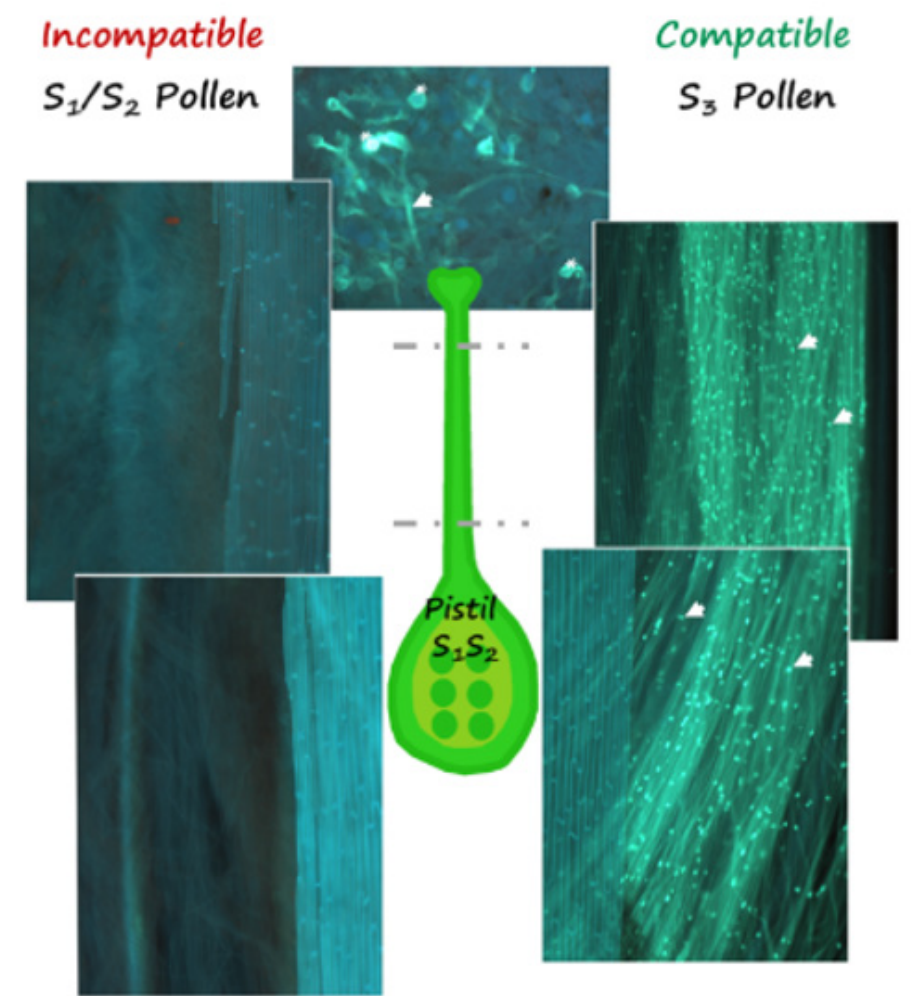

Figure 1: S-specific pollen rejection response in the gametophytic self-incompatibility system (Nicotiana alata). An $S_{1} S_{2}$ plant expresses both $S$ alleles in the pistil and produces pollen with $S_{1}$ and $S_{2}$ haplotypes (50\% each). When the pollen grains (asterisks) land on the stigmatic surface, they germinate, and the pollen tubes (arrows) start to grow through the extracellular matrix of the stylar transmitting tissue. The pistil recognizes and rejects pollen with either $S_{1}$ or $S_{2}$ haplotype (incompatible; left side) at the upper part of the style, preventing homozygotes in the progeny. By contrast, if the pollen portrays a different haplotype $\left(e . g . S_{3}\right)$, it will be allowed to grow and reach the ovary to exert fertilization (compatible; right side), ensuring heterozygotes in the progeny. For these images, $N$. alata pistils were hand-pollinated with incompatible or compatible pollen. After $36 \mathrm{~h}$, pistils were squashed in a blue aniline solution to stain the pollen tube wall and observed under fluorescence microscopy.

SSI has been deeply studied in Brassicaceae. The research on this has identified both $S$ determinants, how they interact, and determined the resultant signaling cascade triggered in an incompatible cross that prevents pollen germination on the stigmatic surface [rev. in 5,10,12,13]. On the other hand, two types of GSI control have been described: the Papaver SI system, only known and studied in Papaver rhoeas, and the S-RNase-based SI system, investigated in Plantaginaceae, Rosaceae, Rubiaceae, Rutaceae, and Solanaceae [9].

\section{GSI $S$ determinants and other participants}

In $P$. rhoeas, the female $S$ determinant encodes a stigma-specific secreted small protein called PrsS [14], which presumably interacts with the pollen $S$ determinant, PrpS, a putative membrane protein specifically expressed in pollen [15]. In an incompatible cross, the $S$-specific interaction between the specificity determinants leads to a rapid increase of intracellular calcium concentration that triggers a series of biochemical and cellular changes, including cytoskeleton rearrangements [16], that end in the pollen programmed cell death 
(PCD) [17], resulting in pollen tube (PT) inhibition at the stigma level.

All the hallmarks of pollen rejection response in $P$. rhoeas are observed when PrsS and PrpS are heterologous expressed in Arabidopsis thaliana $[18,19]$. It suggests that the Papaver SI system uses common proteins for the signal cascade and that the only SIspecific proteins are the $S$-determinants themselves.

The S-RNase-based SI system has been studied in Solanaceae, particularly in Nicotiana and Petunia. Both self- (incompatible) and non-self (compatible) pollen can germinate on the stigmatic surface (Figure 1), and the PTs begin their journey towards the ovary through the extracellular matrix (EM) of the stylar transmitting tissue (STT). However, when the pollen matches the $S$-haplotype with one of the two $S$ alleles in the pistil, the PT growth is inhibited within the first third of the style, preventing self-fertilization (Figure 1).

The female $S$-determinant is a glycoprotein with ribonuclease activity, called S-RNase [20,21]. The S-RNase is specifically expressed in STT cells with a final localization onto the EM [20]. During PT growth through the EM of the STT, S-RNases are taken up by both self- and non-self-PTs $[22,23]$. S-RNases function as cytotoxins degrading the PT RNA in an incompatible cross [24].

The $S$-pollen determinant comprises a suite of proteins called SLF (S-Locus F-box proteins), and pollen grain expressed [25-28]. SLF proteins contain an F-box domain at their N-termini and work as E3 ligase proteins within the SCF (Skp1-Cullin-F-box) complex, which is involved in ubiquitylation of target proteins, leading to their degradation through the proteasome 26S [29].

The pollen rejection specificity relies on $S$-specific interaction between the S-RNase and some of the SLF proteins [30]. However, genetic, biochemical, and cellular evidence indicate that other genes unlinked to the $S$ locus, known as modifier genes (MGs), are required to reject the pollen in an $S$-specific manner successfully. So far, nine MGs have been identified. Four of them are pistil-expressed genes: HT-B, 120K, NaStEP, and NaTrxh [31-34]; and five from the pollen side: PhUBC1, SSK1, MdABCF, PiCUL1-G, and NaSIPP [29,3538]. Their function in pollen rejection was proved by gain and loss of function assays in transgenic plants.

\section{Discussion}

\section{GSI S-RNase-based SI, an intricated system}

The S-RNase-based SI system appears to be quite complicated to dissect. First, it has not been possible to establish a clear in vitro or semi-in vitro assay, like in P. rhoeas, that allow elucidating in a clear and more accessible manner the complex interactions during SI response in different families such as Solanaceae and Rosaceae.

The first identified MG, HT- $B$, encodes a small asparaginerich pistil-expressed protein that, when suppressed, the SI phenotype is lost [31], which means that it is directly involved in $S$-specific pollen rejection. Although its biochemical role is unknown, it is incorporated into the PT, whether it is a compatible or an incompatible cross [23]. However, its stability within PT depends on the type of cross. While in an incompatible PT, HT-B is degraded, it remains stable when it is a compatible one [23,33], in agreement with the results obtained by genetic suppression. If HT-B is hydrolyzed, the PT will reach the ovary. A similar pattern is observed with the arabino galactoprotein $120 \mathrm{~K}$, encoded by other pistil MG [32], but in this case, $120 \mathrm{~K}$ is stabilized in compatible PTs and disappears in incompatible ones [23].

The degradation/stabilization of HT-B and $120 \mathrm{~K}$ indicates that proteolytic activity is essential during SI. Likewise, NaStEP, another pistil-expressed MG, encodes a proteinase inhibitor [39,40]. When NaStEP is suppressed in Nicotiana transgenic plants, the ability to reject self-pollen is abolished. In the absence of NaStEP, the HT-B protein is degraded in PT of both compatible and incompatible crosses, suggesting that NaStEP positively regulates HT-B stability in PT [33], inhibiting probably to a putative pollen protease $[33,40]$. However, direct evidence of this is lacking.

NaTrxh encodes a thioredoxin (Trx) type $h$ with expression in several plant organs, including the pistil. This Trx localizes onto the EM of the STT [41]. NaTrxh interacts and reduces S-RNase in vitro and it has been proved that this reduction results in a seven-fold increase on its ribonuclease activity $[34,41,42]$. When Nicotiana transgenic plants co-express a non-functional NaTrxh variant with its active site mutated, the SI response is disrupted, indicating that its redox activity is essential to pollen rejection in an $S$-specific manner [34].

\section{Models pretending to explain the molecular basis of pollen rejection}

The collaborative and compartmentalization models pretend to explain the molecular basis of pollen rejection response in $\mathrm{S}$-RNase-based systems. The collaborative one states that the pollen rejection response only depends on the $S$-nonspecific interaction between SLF and S-RNase in PT, which leads to the ubiquitylation and degradation of non-self-S-RNase in a compatible cross [30,43]. Here, a suite of 16 to $20 \mathrm{SLF}$ proteins collaborate to identified nonself-S-RNases, which will be ubiquitylated and degraded through the $26 \mathrm{~S}$ proteasome pathway. In contrast, in an incompatible cross, self-S-RNase will not be recognized by any of the collection of SLFs in the PT and will escape proteasome degradation, remaining active to hydrolyze the PT RNA and, therefore, inhibiting PT growth towards the ovary [30]. Under this model, no MG is considered at any step of the pollen rejection leading cascade.

In contrast, the compartmentalization model states that $\mathrm{S}$-RNases are sequestered within a vacuole when incorporated into the PT cytosol. If the cross is compatible, this vacuole will remain intact, preventing the S-RNase cytotoxic activity, and no RNA degradation will occur. By contrast, when the cross is incompatible, the vacuole will be broken down, releasing S-RNase into the cytosol, where they will degrade RNA [23]. The breaking down of the containing S-RNases vacuole will depend on the $S$-specific interaction between SLF and S-RNase. 
Moreover, the pistil proteins HT-B and NaStEP and the pollen protein NaSIPP play a crucial role in the biochemical mechanism that results in self-pollen recognition $[31,33,38]$. Functional assays provide evidence that HT-B is an essential protein in the breakdown of the S-RNase-containing vacuole because, in its absence, the integrity of this vacuole persists [23]. Besides, the stability of HT-B in incompatible PTs depends on the presence of NaStEP, likely inhibiting the protease activity that degrades HT-B in compatible PT through its proteinase inhibitor activity $[33,40]$.

NaStEP seems to be a multifunctional protein because a fraction of it interacts with NaSIPP, a mitochondrial phosphate carrier. When NaSIPP is suppressed in transgenic Nicotiana, the $S$-specific pollen recognition is disrupted [38]. Furthermore, NaStEP also has activity as a voltage-dependent channel blocker [40]. Taken together, we propose that PCD might be involved in the pollen rejection response in Nicotiana. We hypothesize that the PCD mechanism in an incompatible cross is initiated by the $S$-specific interaction between SLF and S-RNase, through NaStEP, which with its inhibitor proteinase function, will inhibit the protease that hydrolyzes HT-B $[33,40]$, a necessary step to breakdown the S-RNase containing vacuole. Likewise, another fraction of NaStEP will impair the mitochondria through its interaction with NaSIPP [38] and some voltage-dependent channel [40], which will trigger the PCD that concludes with the disruption of the S-RNase-containing vacuole, probably through HT-B participation. Finally, once in the cytosol, S-RNases will be further activated by the reduction of one of their disulfide bridges by NaTrxh $[34,44]$.

While the collaborative model evidence has mainly raised from research on Petunia, the compartmentalization model evidence is from Nicotiana. Both species belong to the Solanaceae family but, according to several phylogenetic analysis, are grouped in two different subfamilies [45,46].

\section{Conclusion}

Both collaborative and compartmentalization models seem to be excluding each other. While the collaborative model proposes that the $S$-nonspecific interaction between SLF and S-RNase protects compatible pollen; the compartmentalization model claims that the $S$-specific interaction between the specificity determinants, which triggers self-pollen rejection through a signal cascade downstream this interaction where the MG products are involved.

It calls attention that Petunia and Nicotiana SI mechanisms be so different because both belong to different subfamilies within Solanaceae $[45,46]$. One possible scenario is that, indeed, it does. Still, another option is that the collaborative model is limited to the S-RNase degradation because S-RNase compartmentalization and MG function, such as HT-B, NaStEP, NaSIPP, and NaTrxh, have not yet been evaluated in Petunia. Therefore, the question remains open, and more forth research in this direction is needed.

\section{Acknowledgement}

FC-G envisioned the idea. All authors contributed to discussion and wrote the manuscript. The work was funded by grants from FQ-5000-9128 and PAPIIT-UNAM (IN220919 and IN230920).

\section{Conflict of Interest}

The authors declare that there is not any competing interest.

\section{References}

1. de Nettancourt D (1977) Incompatibility in angiosperms. (1 $1^{\text {st }}$ edn), Springer-Verlag, Heidelberg, Berlin, Germany, p. 232.

2. de Nettancourt D (2001) The genetics of self-incompatibility. In: de Nettancourt D (Ed.), Incompatibility and incongruity in wild and cultivated plants. (edn), Springer Verlag, Heidelberg, Berlin, Germany, pp: 25-72.

3. Darwin CR (1877) The different forms of flowers on plants of the same species. ( $1^{\text {st }}$ edn), John Murray, London, p. 352.

4. Gibbs PE (1986) Do homomorphic and heteromorphic selfincompatibility systems have the same sporophytic mechanism? Pl Syst Evol 154: 285-323.

5. Takayama S, Isogai A (2005) Self-incompatibility in plants. Annu Rev Plant Biol 56: 467-489.

6. McClure B, Cruz García F, Romero C (2011) Compatibility and incompatibility in S-RNase-based systems. Ann Bot 108(4): 647-658.

7. Lundqvist A (1954) Studies on self-sterility in rye, Secale cereale L. Hereditas 40(3-4): 278-294.

8. Hayman DL (1956) The genetic control of incompatibility in Phalaris coerulescens DESF. Aust J Biol Sci 9(3): 321-331.

9. McClure BA, Franlin Tong V (2006) Gametophytic self-incompatibility: understanding the cellular mechanisms involved in "self" pollen tube inhibition. Planta 224(2): 233-245.

10. Hiscock SJ, Tabah DA (2003) The different mechanisms of sporophytic self-incompatibility. Philos Trans R Soc Lond B Biol Sci 358(1434): 1037-1045.

11. Rea AC, Nasrallah JB (2008) Self-incompatibility systems: barriers to self-fertilization in flowering plants. Int J Dev Biol 52(5-6): 627-636.

12. Hiscock SJ, McInnis SM (2003) Pollen recognition and rejection during the sporophytic self-incompatibility response: Brassica and beyond. Trends Plant Sci 8(12): 606-613.

13. Ivanov R, Fobis Loisy I, Gaude T (2010) When no means no: guide to Brassicaceae self-incompatibility. Trends Plant Sci 15(7): 387-394.

14. Foote HC, Pride JP, Franklin Tong VE, Walker EA, Lawrence MJ, etal. (1994) Cloning and expression of a distinctive class of self-incompatibility $(S)$ gene from Papaver rhoeas L. Proc Natl Acad Sci USA 91(6): 2265-2269.

15. Wheeler MJ, de Graaf BHJ, Hadjiosif N, Perry RM, Poulter N, et al. (2009) Identification of the pollen self-incompatibility determinant in Papaver rhoeas. Nature 459(7249): 992-995.

16. Poulter NS, Vatovec S, Franklin Tong VE (2008) Microtubules are a target for self-incompatibility signaling in Papaver pollen. Plant Physiol 146(3): 1358-1367.

17. Thomas SG, Franklin Tong VE (2004) Self-incompatibility programmed cell death in Papaver pollen. Nature 429(6989): 305-309.

18. de Graaf BHJ, Vatovec S, Juárez Díaz JA, Chai L, Kooblall K, et al. (2012) The Papaver self-incompatibility pollen $S$-determinant, $\operatorname{PrpS}$, functions in Arabidopsis thaliana. Curr Biol 22(2): 154-159.

19. Lin Z, Eaves DJ, Sanchez Moran E, Franklin FCH, Franklin Tong VE (2015) The Papaver rhoeas $S$ determinants confer self-incompatibility to Arabidopsis thaliana in planta. Science 350(6261): 684-687.

20. Anderson MA, Cornish EC, Mau SL, Williams EG, Hoggart R, et al. (1986) Cloning of cDNA for a stylar glycoprotein associated with expression of self-incompatibility in Nicotiana alata. Nature 321: 38-44.

21. McClure BA, Haring V, Ebert PR, Anderson MA, Simpson RJ, et al. (1989) Style self-incompatibility gene products of Nicotiana alata are ribonucleases. Nature 342(6252): 955-957. 
22. Luu DT, Qin X, Morse D, Cappadocia M (2000) S-RNase uptake by compatible pollen tubes in gametophytic self-incompatibility. Nature 407(6804): 649-651.

23. Goldraij A, Kondo K, Lee CB, Hancock CN, Sivaguru M, et al. (2006) Compartmentalization of S-RNase and HT-B degradation in selfincompatible Nicotiana. Nature 439(7078): 805-810.

24. McClure BA, Gray JE, Anderson MA, Clarke AE (1990) Self-incompatibility in Nicotiana alata involves degradation of pollen rRNA. Nature 347: 757760 .

25. Lai Z, Ma W, Han B, Liang L, Zhang Y, et al. (2002) An F-box gene linked to the self-incompatibility (S) locus of Antirrhinum is expressed specifically in pollen and tapetum. Plant Mol Biol 50(1): 29-42.

26. Qiao H, Wang F, Zhao L, Zhou J, Lai Z, et al. (2004) The F-box protein AhSLF-S $_{2}$ controls the pollen function of S-RNase-based selfincompatibility. Plant Cell 16(9): 2307-2322.

27. Wheeler D, Newbigin E (2007) Expression of $10 S$-class SLF-like genes in Nicotiana alata pollen and its implications for understanding the pollen factor of the $S$-locus. Genetics 177(4): 2171-2180.

28. Williams JS, Der JP, dePamphilis CW, Kao TH (2014) Transcriptome analysis reveals the same $17 \mathrm{~S}$-locus F-box genes in two haplotypes of the self-incompatibility locus of Petunia Inflata. Plant Cell 26(7): 28732888.

29. Hua ZH, Kao TH (2006) Identification and characterization of components of a putative Petunia S-locus F-box-containing $\mathrm{E}_{3}$ ligase complex involved in S-RNase-based self-incompatibility. Plant Cell 18(10): 2531-2553.

30. Kubo Ki, Entani T, Takara A, Wang N, Fields AM, et al. (2010) Collaborative non-self recognition system in S-RNase-based self-incompatibility. Science 330(6005): 796-799.

31. McClure B, Mou B, Canevascini S, Bernatzky R (1999) A small asparaginerich protein required for S-allele-specific pollen rejection in Nicotiana. Proc Natl Acad Sci USA 96(23): 13548-13553.

32. Hancock CN, Kent L, McClure B (2005) The stylar 120 kDa glycoprotein is required for $S$-specific pollen rejection in Nicotiana. Plant J 43(5): 716723.

33. Jiménez Durán K, McClure B, García Campusano F, Rodríguez Sotres R, Cisneros J, et al. (2013) NaStEP: A proteinase inhibitor essential to selfincompatibility and a positive regulator of HT-B stability in Nicotiana alata pollen tubes. Plant Phys 161(1): 97-107.

34. Torres Rodríguez MD, Cruz Zamora Y, Juárez Díaz JA, Mooney B, McClure BA, et al. (2020) NaTrxh is an essential protein for pollen rejection in Nicotiana by increasing S-RNase activity. Plant J 103(4): 1304-1317.
35. Zhao L, Huang J, Zhao Z, Li Q Sims TL, et al. (2010) The Skp1-like protein SSK1 is required for cross-pollen compatibility in $S$-RNase-based selfincompatibility. Plant J 62(1): 52-63.

36. Meng D, Gu Z, Li W, Wang A, Yuan H, et al. (2014) Apple MdABCF assists in the transportation of S-RNase into pollen tubes. Plant J 78(6): 9901002 .

37. Li S, Williams JS, Sun P, Kao TH (2016) All 17 S-locus F-box proteins of the $S_{2}$ - and $S_{3}$-haplotypes of Petunia inflata are assembled into similar SCF complexes with a specific function in self-incompatibility. Plant J 87(6): 606-616.

38. García Valencia LE, Bravo Alberto CE, Wu HM, Rodríguez Sotres $\mathrm{R}$, Cheung AY, et al. (2017) SIPP, a novel mitochondrial phosphate carrier, mediates in self-incompatibility. Plant Phys 175(3): 1105-1120.

39. Busot GY, McClure B, Ibarra Sánchez CP, Jiménez Durán K, Vázquez Santana S, et al. (2008) Pollination in Nicotiana alata stimulates synthesis and transfer to the stigmatic surface of NaStEP, a vacuolar Kunitz proteinase inhibitor homologue. J Exp Bot 59(11): 3187-3201.

40. Cruz Zamora Y, Nájera Torres E, Noriega Navarro R, Torres Rodríguez MD, Bernal Gracida LA, et al. (2020) NaStEP, an essential protein for selfincompatibility in Nicotiana, performs a dual activity as a proteinase inhibitor and as a voltage-dependent channel blocker. Plant Physiol Biochem 151: 352-361.

41. Juárez Díaz JA, McClure B, Vázquez Santana S, Guevara García A, León Mejía P, et al. (2006) A novel thioredoxin $h$ is secreted in Nicotiana alata and reduces S-RNase in vitro. J Biol Chem 281(6): 3418-3424.

42. Ávila Castañeda A, Juárez Díaz JA, Rodríguez Sotres R, Bravo Alberto CE, Ibarra Sánchez CP, et al. (2014) A novel motif in the NaTrxh N-terminus promotes its secretion, whereas the C-terminus participates in its interaction with S-RNase in vitro. BMC Plant Biol 14: 147.

43. Qiao H, Wang H, Zhao L, Zhou J, Huang J, et al. (2004) The F-box protein AhSLF-S 2 physically interacts with S-RNases that may be inhibited by the ubiquitin/26S proteasome pathway of protein degradation during compatible pollination in Antirrhinum. Plant Cell 16(3): 582-595.

44. Torres Rodríguez MD, González Segura L, Rodríguez Sotres R, Juárez Díaz JA, Cruz Zamora Y, et al. (2020) High resolution crystal structure of NaTrxh from Nicotiana alata and its interaction with the S-RNase. J Struct Biol 212(1): 107578.

45. Olmstead RG, Bohs L, Migid HA, Santiago Valentin E, Garcia VF, et al. (2008) A molecular phylogeny of the Solanaceae. Taxon 57(4): 11591181.

46. Zhang J, Stevens PF, Zhang W (2017) Evolution of floral zygomorphy in androecium and corolla in Solanaceae. J Syst Evol 55(6): 581-590. 